\title{
Relationship between Bitcoin Exchange Rate and Other Financial Indexes in Time Series
}

\author{
Chien-Yun Chang, ${ }^{1}$ Chien-Chien Lo, ${ }^{2}$ Jui-Chang Cheng, ${ }^{3}$ Tzer-Long Chen ${ }^{\mathbb{D}}{ }^{4}$ \\ Liang-Yun Chi, ${ }^{5}$ and Chih-Cheng Chen ${ }^{60}{ }^{6,7}$ \\ ${ }^{1}$ Department of Fashion Business and Merchandising, Ling Tung University, Taichung, Taiwan \\ ${ }^{2}$ Department of International Business, Providence University, Taichung 43301, Taiwan \\ ${ }^{3}$ Department of Leisure and Recreation Management, National Taichung University of Science and Technology, Taichung, Taiwan \\ ${ }^{4}$ Department of Finance, Providence University, Taichung, Taiwan \\ ${ }^{5}$ Department of Finance, National Taichung University of Science and Technology, Taichung, Taiwan \\ ${ }^{6}$ Department of Automatic Control Engineering, Feng Chia University, Taichung 40724, Taiwan \\ ${ }^{7}$ Department of Aeronautical Engineering, Chaoyang University of Technology, Taichung 413310, Taiwan
}

Correspondence should be addressed to Tzer-Long Chen; tlchen1976@pu.edu.com and Chih-Cheng Chen; ccc@gm.cyut.edu.tw Received 29 October 2020; Revised 21 February 2021; Accepted 5 April 2021; Published 29 April 2021

Academic Editor: Teen-Hang Meen

Copyright ( $) 2021$ Chien-Yun Chang et al. This is an open access article distributed under the Creative Commons Attribution License, which permits unrestricted use, distribution, and reproduction in any medium, provided the original work is properly cited.

\begin{abstract}
The Bitcoin exchange rate (BER) is influenced by many variables such as human speculation and policies and, thus, is dependent on the financial system. The fluctuation of BER submitted has been extensively investigated. However, the correlation analysis of the short- and long-term effects by indicators of online sentiment is unexplored. Therefore, this study establishes a VAR model for BER which provides a framework to the Google search volume index (SVI), the investor fear gauge (VIX), and the S\&P500 Index. The findings of the analysis suggest that BER and Google SVI have a Granger causality feedback relationship in both the short- and long-term co-integration equilibrium, and the VIX is significantly related to BER in the long-term co-integration.
\end{abstract}

\section{Introduction}

The Bitcoin exchange rate (BER) is extremely volatile. As shown in Figure 1, BER to the US dollar from October 01, 2013 , to June 22, 2018, increased by nearly 2 million times from less than USD 0.01 to 19,345.49 on December 16, 2017. Kurka concluded that BER is independent of any financial asset classes in the system, but its spillover effect affected the traditional financial markets [1].

The pricing models of stock price or exchange rate have assumptions of transactions by rational investors. However, researchers pointed out that investment decisions made by investors are not necessarily rational. Thus, behavioral financial theories emerged to explain irrational decisions. For example, Barber and Odean proposed the "Attention Theory" that explained investors' intention of buying stocks without having time to interpret the disclosure of massive information on the stocks [2]. Merton suggested the "Investor Recognition Hypothesis" that stated the information spillover effect of investors' stock buying on the firm's visibility [3]. The higher the visibility of a firm, the more the interest investors have in the stock. It yields higher price returns and greater trading volume. Cai et al. proved that Google SVI of Bitcoin had a significant impact on its price and transaction volume as the proxy explanatory variable of “investor focus" [4].

This research employs the vector autoregression (VAR) model to explore the long- and short-term relationship between the Google SVI and BER. The key variables are studied by applying the theoretical basis of "investor attention" that influences BER. Based on the findings of the current research, the important variables of traditional financial assets are selected in consideration of the volatility index (VIX), the S \& P500 index, and the Google SVI. The 


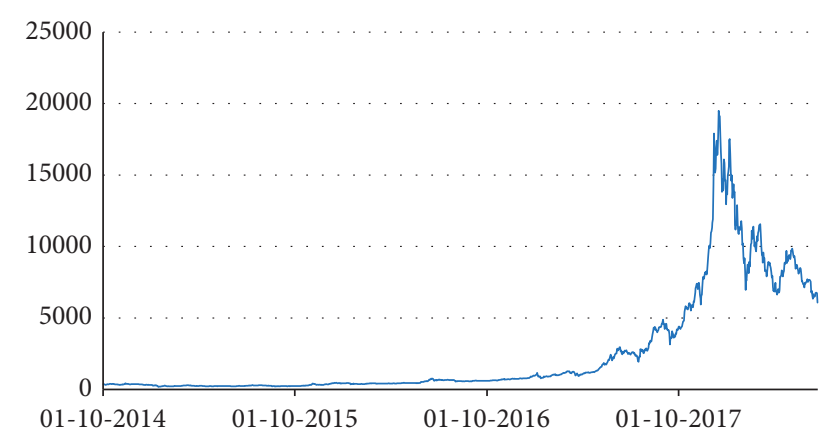

Figure 1: Bitcoin exchange rate chart (10/01/2014-06/22/2018).

vector autoregression (VAR) analysis of the short- and longterm impacts and Granger causal relationship ([5-7]) are employed to develop a prediction model for BER change for providing a reference for Bitcoin hedging operation to investors. The BER is a new investment tool with higher volatility to the traditional financial product. Investors have little hedge and others reference target to avoid the risk of BER. The forecasting model of BER can offer mostly relation financial products and be applied for hedge, arbitrage for investors. The result expected the SVI should have higher relationship in the short and long periods.

This article is organized as follows: Section 2 reviews previous references and discusses the relation of the Google SVI and VIS, in variable explanation to Bitcoin. Section 3 presents the VAR for the data analysis as the research method. Section 4 describes the analysis results. Finally, Section 5 concludes this article.

\section{Literature Review}

2.1. Google SVI. Urquhart [8] and Bleher and Dimpfl [9] adopted Google SVI as a proxy explanatory variable for "investor attention" for studying 12 cryptocurrencies including Bitcoin. The other researchers also employed Google SVI to measure investor attention $[10,11]$.

Since "Google Trends" was first introduced, the number of searches was queried by entering the targeted word. Later on, Google launched "Google Insights for Search" which divided the data into detailed categories such as time and geographical regions. "Google Insights for Search" became the current Google Trend in September 2012. The time range for searching is customized or selected in the past 1, 4 hours, $1,7,30,90$, and 5 years. Up to 5 keywords are analyzed simultaneously. The search items are searched for their trends in a single country or all over the world. The categories are selected by the industry of interest or all categories. After determining the keywords, region, periods, and categories, Google Trends generate a trend chart with a standard quantitative range from 0 to 100 and calculate the SVI data based on the average time series, but the data frequency is a week.

SVI calculation formula is as follows:

SVI $=\frac{\text { total search volume }}{\text { maximum total search volume in a given time period }} \times 100$.
The SVI may yield different results for the same keywords according to different query, time, date, and geographic location. When Google compiles SVI data, it does not search all data but randomly selects samples. However, different results did not change the research outcomes [12]. Takeda and Wakao present the SVI has a positive impact on the stock price and volume [13]. Aouadi et al. using Google search volume to evidence the relationship among the attention of French stock market investors and trading volume, stock market illiquidity, and volatility [10].

Zhang et al. pointed out that the long-term prices converged to the mean reversion when stock prices rose solely with increased investor attention [14]. To understand whether the mean reversion of BER is related to Google SVI, we selected Google SVI as the proxy interpretation variable for "investor focus". Details are shown in Figure 2.

2.2. VIX. The Volatility Index (VIX) is compiled by the COBE Exchange that implies volatility of future options on the S\&P500 and reflects the degree of risk in the stock market over the next 30 days. The VIX greater than 40 indicates that market investors expect a strong fluctuation of stock index in the future, that is, irrational panic. When the index is less than 15 , it means the investors believe the volatility in the future stock market to be mild which shows irrational exuberance. As it reflects the traders' expectations on future stock price change, it is also called the "Fear Index" or "The Investor Fear Gauge."

Qadan et al. believed that VIX reflected the investors' sentiment. In a period of extreme uncertainty, investors tend to be more risk-averse and therefore need higher idiosyncratic volatility (IVOL) premium at a high level of VIX [15]. Under the circumstance, investors avoid stocks of high IVOL, which results in lower investment returns with high IVOL than with low IVOL. Tsai et al. also found the reversed prices in the future led to significant negative investment loss when investors overestimated stock prices positively [16]. Simon and Wiggins showed that the VIX index was used to predict the future stock market [17]. Lee pointed the new sentiment of the current period has a positive relationship with investment reports, and the new sentiment of the lagged period has a negative relationship with investment aspirations [18]. Copeland and Copeland noted that COBE Volatility Index (VIX) can be treated as leading index of stock price index [19]. Dennis et al. treated VIX is a proxy variable of stock return volatility [20]. When the VIX soars and the market shows extreme fear, it would be the best opportunity to enter the stock market.

This research includes the VIX by Chicago Board Options Exchange (COBE) as a proxy explanatory variable for investor sentiment in an empirical study to understand the impact of investor sentiment on the BER.

2.3. Bitcoin. Kurka studied the interaction between Bitcoin and traditional finance assets [1]. The results showed that BER was independent of any financial system assets. Though traditional financial assets had little impact on the BER 


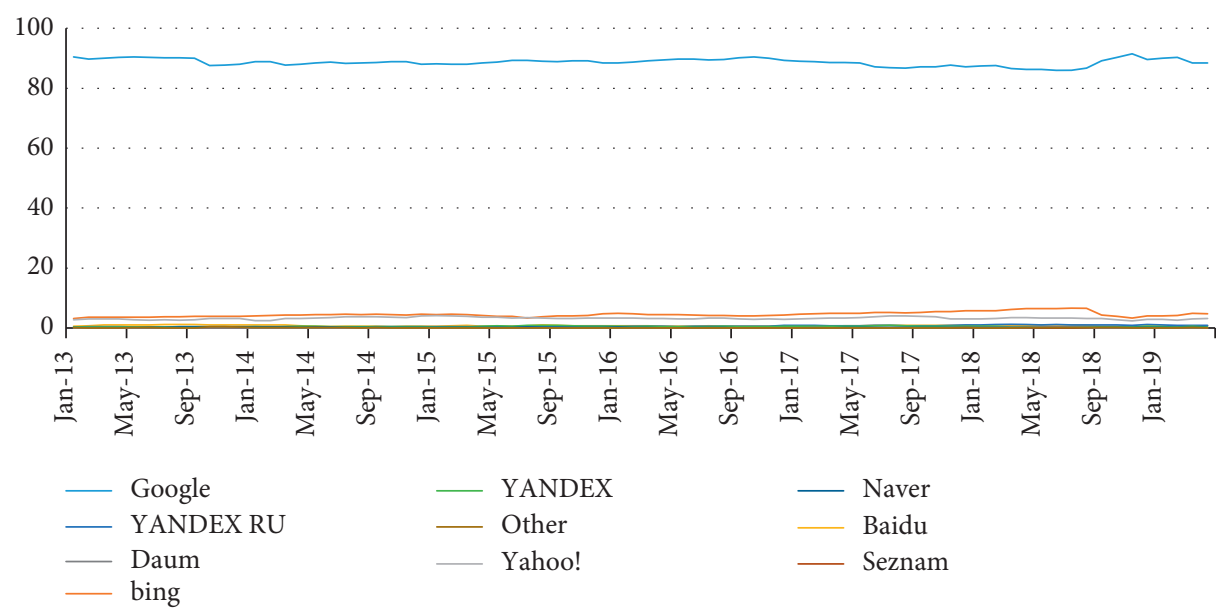

FIGURE 2: Google search engine market share worldwide (2013/1-2019/4, Source: http://gs.statcounter.com).

trend, the spillover effect of BER was significant in the traditional financial market.

Cai et al. adopted the Google SVI as the proxy explanatory variable for investors' decisions [4]. The results supported that the SVI had a vital influence on the price and volume of Bitcoin. Dastgir et al. surveyed Google Trends search flow on Bitcoin [21]. It employed the Granger causality to test the causal relationship between the interest in Bitcoin and investment returns. The conclusion supported the existence of bidirectional causality between Bitcoin and investment returns.

This study analyzed the short- and long-term relationship between Google SVI and BER by the VAR model. The longterm relationship among BER, VIX, and the S\&P500 index was also investigated for a co-integration phenomenon.

\section{Methodology and Model}

The research process was divided into two aspects as shown in Figure 3. For the short-term impact analysis, the VAR model and Granger causality were employed to test the explanatory variables of BER and verify their relationship, respectively. For the long-term impact, Nelson and Plosser argued that the variable difference was lost in the implicit information on the long-term equilibrium through the stationary sequence [22]. Therefore, the co-integration analysis and vector error correction model (VECM) validated the long-term relationship between the variables.

3.1. VAR Model and VECM. The VAR model in this study is defined as follows:

$$
y_{t}=c+\sum_{t=1}^{n} \varphi_{i} y_{t-1}+\varepsilon_{t}
$$

where $y_{t}$ is a $(n \times 1)$ vector of endogenous variables, $c=\left(c_{1}, \ldots . ., c_{n}\right)$ is the $(n \times 1)$ intercept vector of the VAR, $\varnothing_{t}$ is the $i$-th $(n \times n)$ matrix of autoregressive coefficients for $i=1$, $2, \ldots, n$, and $\varepsilon_{t}=\left(\varepsilon_{1} \ldots \varepsilon_{t}\right)$ is the $(n \times 1)$ generalization of a white noise process [24].

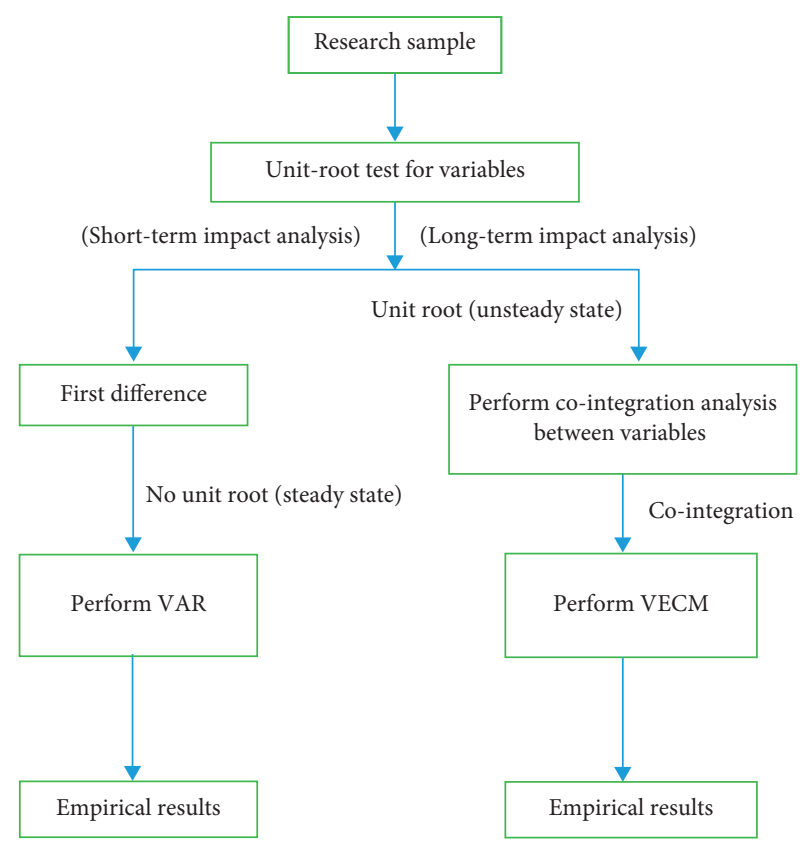

Figure 3: Flow chart of this research [23].

The following equation is the co-integration transformation of equation (2).

$$
\Delta y_{t}=\Pi y_{t-1}+\sum_{i=1}^{p-1} \Phi \Delta y_{t-i}+\mu_{t}
$$

where $\Pi=\sum_{i=1}^{p} \varphi_{i}-I$ and $\Phi=\sum_{i+1}^{p} \varphi_{j}$.

If $y_{t}$ has a co-integration relationship, then $\Pi y_{t-1} \sim I(0)$ and equation (3) is expressed as follows:

$$
\Delta y_{t}=\alpha \beta^{\prime} y_{t-1}+\sum_{i=1}^{p-1} \Phi \Delta y_{t-i}+\mu_{t},
$$

where $\beta^{\prime} y_{t-1}=\mathrm{ECM}_{t-1}$ is the error correction term for a long-term equilibrium relationship between variables. Equation (4), then, becomes 


$$
\Delta y_{t}=\alpha \mathrm{ECM}_{t-1}+\sum_{i=1}^{p-1} \Phi \Delta y_{t-i}+\mu_{t} .
$$

Equation (5) is used for the vector error correction model (VECM) in which each equation belongs to an error correction model [25].

Before establishing the VAR model, it is necessary to choose the optimal lagged periods. The criteria include Akaike's Information Criterion (AIC), Hannan-Quinn Criterion (HQ), Schwarz Criterion (SC) likelihood ratio (LR), and so on. However, the Akaike proposed the AIC method and SC method which are most used [26]. The equations of the AIC and SC criteria are defined as follows:

$$
\begin{aligned}
\mathrm{AIC} & =\ln \left(\frac{\mathrm{SSE}}{T}\right)+\left(\frac{2 k}{T}\right), \\
\mathrm{SC} & =\ln \left(\frac{\mathrm{SSE}}{T}\right)+\left(\frac{k}{T} \ln T\right),
\end{aligned}
$$

where $k$ is the number of all parameters to be estimated by the VAR model. The number of periods corresponding to the minimum value of the measurement of AIC or SC is the optimal number of lagged terms. The AIC is more consistent than SC. However, as the estimated parameters of the AIC are less and the number of samples is larger than the SC, the $\mathrm{SC}$ is better than the AIC for this research.

\subsection{Multivariate Granger Causality Analysis.} Multivariate Granger causality analysis is performed by fitting a VAR model to the time series. Let $\mathrm{X}(t) \in \mathfrak{R}^{d \times 1}$ $(t=1, \ldots, T)$ be a $d$-dimensional multivariate time series. Multivariate Granger causality is measured by fitting a VAR model to $L$ time lags as follows:

$$
\mathrm{X}(t)=\sum_{\lambda=1}^{L} \Phi_{\lambda} \mathrm{X}(t-\lambda)+\nu_{t}
$$

where $v_{t}$ is a white Gaussian random vector and $\Phi_{\lambda}$ is a matrix for every $\lambda$. A time series $X_{i}$ is called a Granger cause of another time series $X_{j}$, if at least one of the elements $\Phi_{\lambda}(i, j)$ is significantly larger than zero.

3.3. Data Source and Sample Collection Period. This research mainly discussed the key factors that affect the changes in BER by referring to Cai et al. [4], Kurka [1], and Hsieh [27]. The main variables included Google SVI, the VIX of Chicago Board of Exchange, S\&P500 index, gold prices, US dollar index, and Japanese exchange rate. The period for sampling was from April 29, 2013, to June 22, 2018. The data sources were Yahoo Finance and Bloomberg. The data frequency was a day, and the data processing method did not affect the final results. If there was no observation value for any variable on the same day, the data of that day were deleted [28]. A total of 1,299 daily observation values for each variable were used.

\section{Analysis Results and Discussion}

The analysis was carried out in two processes as shown in Figure 4. We used the VAR model and Granger causality to test the explanatory stationary time series variables for the short-term impact. Then we used the co-integration analysis and vector error correction model (VECM) to validate the long-term relationship between the nonstationary variables. The descriptive statistics, VAR model analysis, and the cointegration relationship were performed and illustrated below.

4.1. Descriptive Statistics. Table 1 shows standard deviation, and maximum and minimum BER, gold price (GOLD), USD/JPY exchange rate (JPY), S\&P500 index (SP500), Google SVI, US dollar index (USD), and VIX during the study period.

\subsection{Short-Term VAR Analysis}

4.2.1. Unit Root Verification. The Augmented Dickey-Fuller (ADF) and the Phillips-Perron (PP) tests ([29, 30]) were applied to the unit root sequence in this study. By taking the natural logarithm and first-order difference, all the variables were in a significant stationary sequence as shown in Table 2.

4.2.2. Optimal Lagging Period Selection. The research employed the AIC to determine the optimal number of two lagged periods. Table 3 shows the details of the optimal lagged periods.

4.2.3. Results of Analysis of the VAR Model. The first-order difference in the variables presents a stationary sequence and is used to analyze the short-term influence of the variables with the VAR model. The results are shown in Table 4. BER of the two lagged periods had a positive impact (0.108278) on the overall BER at a significant level of $1 \%$. The Google SVI had a negative effect $(-0.100983)$ on the BER at a significant level of $1 \%$, while Google SVI has a positive impact (0.064947) on the BER at a significant level of $1 \%$. The S\&P500 index had a negative impact $(-0.108234)$ on the leading two-period S\&P500 index at a significant level of $1 \%$. $p<1,5$, or $10 \%$ of the significant level indicates that the coefficient is not equal to zero, that is, the S\&P500 index Granger causality causes the lag two-period S\&P500 index.

The Granger causality diagram of the short-term variables affected the BER. The results demonstrated that the feedback relationship appeared only in the BER and the Google SVI among the Granger causality as shown in Figure 4 .

\subsection{Long-Term Co-Integration Analysis}

4.3.1. Johansen Maximum Likelihood Co-Integration Test. Nelson and Plosser supposed that a different process caused the time series to lose long-term information [22]. That is, all nonstationary time series become stationary after the 


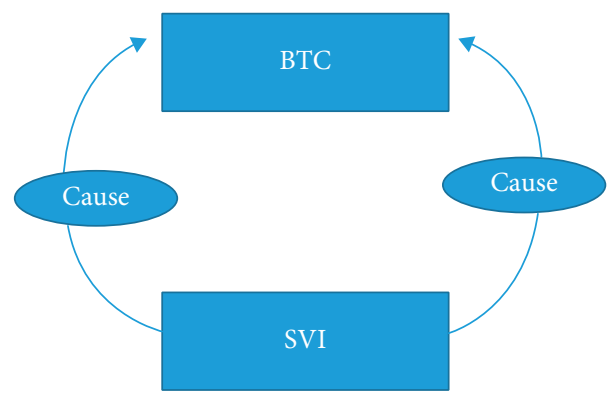

FIGURE 4: Granger causality between short-term variables.

TABLE 1: Variable raw data statistics.

\begin{tabular}{lcccc}
\hline Variables & Average value & Standard deviation & Minimum value & Maximum value \\
\hline BTC & 1916.304 & 3281.969 & 69.66000 & 18972.32 \\
SVI & 7.727833 & 13.16746 & 1.000000 & 100.0000 \\
VIX & 14.62402 & 3.864276 & 9.140000 & 40.74000 \\
SP500 & 2130.599 & 303.6529 & 1573.090 & 2872.870 \\
GOLD & 1252.709 & 76.27864 & 1049.400 & 1469.250 \\
USD & 86.37288 & 6.655887 & 74.52690 & 96.86650 \\
JPY & 110.0013 & 7.632938 & 94.21000 & 125.2200 \\
\hline
\end{tabular}

TABLE 2: The natural logarithm of each variable and the first-order difference unit root verification results.

\begin{tabular}{lcccc}
\hline Variables & \multicolumn{2}{c}{ PDF } & $\mathrm{P}$ & $\mathrm{P}$ \\
\hline BTC & $\mathrm{P}$ & $\mathrm{T}$ & $0.0000^{* * *}$ & $-38.34844^{* * *}$ \\
GOLD & $0.0000^{* * *}$ & $-18.13386^{* * *}$ & $0.0000^{* * *}$ & $-37.76925^{* * *}$ \\
JPY & $0.0000^{* * *}$ & $-37.81181^{* * *}$ & $0.0000^{* * *}$ & $-35.95482^{* * *}$ \\
SP500 & $0.0000^{* * *}$ & $-35.90829^{* * *}$ & $0.0000^{* * *}$ & $-36.69663^{* * *}$ \\
SVI & $0.0000^{* * *}$ & $-36.56911^{* * *}$ & $0.0000^{* * *}$ & $-36.22507^{* * *}$ \\
USD & $0.0000^{* * *}$ & $-35.99486^{* * *}$ & $0.0000^{* * *}$ & $-34.47007^{* * *}$ \\
VIX & $0.0000^{* * *}$ & $-34.30820^{* * *}$ & $0.0001^{* * *}$ & $-42.94997^{* * *}$ \\
\hline
\end{tabular}

Significant level of ${ }^{* * *} 1 \%$.

TABLE 3: The optimal lagged periods selected by stationary sequence.

\begin{tabular}{lcr}
\hline Lagged periods & Information criterion & SC \\
\hline 0 & AIC & $-35.66180^{*}$ \\
1 & -35.68981 & -35.65473 \\
2 & -35.87884 & -35.46100 \\
3 & $-35.88120^{*}$ & -35.24522 \\
4 & -35.86150 & -35.02430 \\
\hline
\end{tabular}

* Selected lagged periods.

first-order difference operation, so it is used to study the short-term influence between variables.

Johansen co-integration test was used to test long-term relationship among the variables, and the Trace test to obtain the number of co-integration vector (CE) equation sets for variables of no difference ([31, 32]). As shown in Table 6, the hypothesis assumes that there is none CE, and the trace statistics shows 226.9521 and larger than the critical value 134.6780 which means reject that there is none CE. Therefore, Table 5 shows that there are two sets of co-integration equations under $5 \%$ critical value that are most relevant to the goodness-of-fit test because the trace statistics shows 75.8209 and smaller than the critical value 76.9727 at most 2, which means that we cannot reject that there are two co-integration vectors.

4.3.2. Vector Error Correction Estimates Model. Through the Johansen Co-integration test, two sets of co-integration vector equations were obtained by using the trace test method. The co-integration vector equation and the VECM are shown in Table 6. The co-integration vector equations 
TABLE 4: Results of analysis by the VAR model.

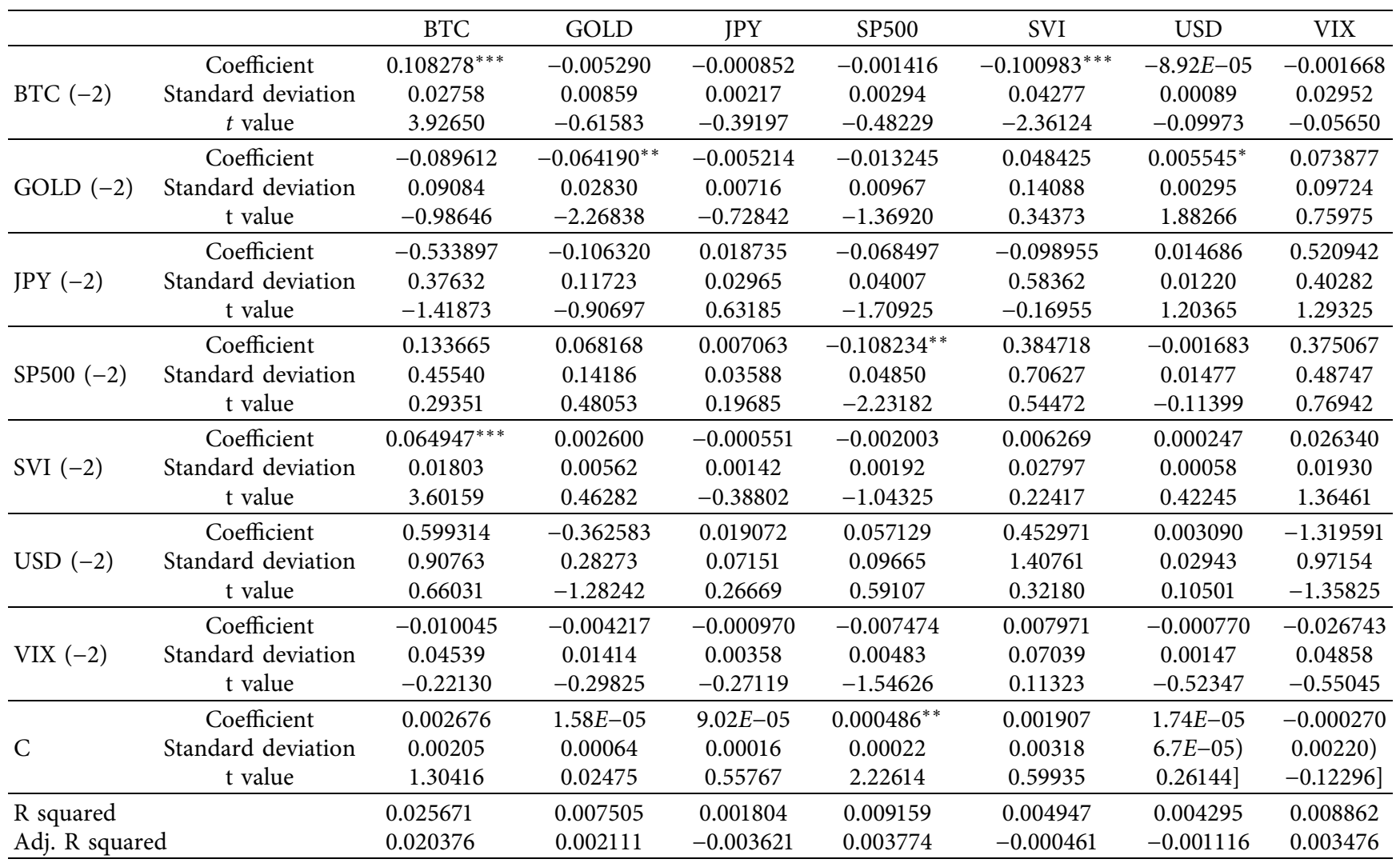

Significant level of ${ }^{* * *} 1 \%,{ }^{* *} 5 \%,{ }^{*} 10 \%$ and the coefficients means the estimated coefficients.

TABLE 5: Johansen maximum likelihood co-integration test result.

\begin{tabular}{|c|c|c|c|c|}
\hline Hypothesized no. of CE(s) & Eigenvalue & Trace statistics & Critical value at $\alpha=0.05$ & Probability \\
\hline None ${ }^{@}$ & 0.065359 & 226.9521 & 134.6780 & $0.0000^{* * *}$ \\
\hline At most $1^{@}$ & 0.04826 & 139.6904 & 103.8473 & $0.0000^{* * *}$ \\
\hline At most 2 & 0.0282 & 75.8209 & 76.9727 & 0.0610 \\
\hline At most 3 & 0.0144 & 38.8515 & 54.0790 & 0.5287 \\
\hline At most 4 & 0.0077 & 20.0129 & 35.1927 & 0.7259 \\
\hline At most 5 & 0.0055 & 9.9263 & 20.2618 & 0.6471 \\
\hline At most 6 & 0.0020 & 2.6882 & 9.16454 & 0.6404 \\
\hline
\end{tabular}

${ }^{* * *}$ Significant level of $1 \%$; ${ }^{\circledR}$ the number of co-integrated equations.

show that equations (2) and (3) are based on the BER and Google SVI, respectively. The coefficients of the equation variables are highly significant to each other.

4.3.3. Long-Term Granger Causality. Granger causality is a statistical concept of causality that is based on VAR. The coefficient of granger causality test is assumed that does not influence between two variables under null hypothesis as shown in Table 7 . If the probability is larger than 0.1 , then we do not reject the null hypothesis, and these two variables do not have granger causality. The results of the granger causality test are shown in Table 7. The BER influenced the S\&P500 index and Google SVI. The Google SVI Granger caused the BER index. Therefore, the BER and SVI presents intergranger causality. The S\&P500 SVI Granger influenced Google SVI. The VIX Granger contributed to the S\&P500 index, the BER index, and the Google SVI. 
TABLE 6: Co-integration vector equation and the VECM.

\begin{tabular}{|c|c|c|c|c|}
\hline Co-integrating equation & & Equation (2) & Equation (3) & \\
\hline BTC & & 1.0000 & 0.0000 & \\
\hline \multirow[t]{2}{*}{ SVI } & & 0.0000 & 1.0000 & \\
\hline & Coefficient & $16.0725^{* * *}$ & $11.3168^{* * *}$ & \\
\hline \multirow[t]{2}{*}{ VIX } & Standard deviation & 2.2836 & 1.5958 & \\
\hline & t value & 7.0381 & 7.0912 & \\
\hline $\mathrm{C}$ & & -49.2158 & -31.4336 & \\
\hline \multirow[t]{2}{*}{ Error correction: } & & $\mathrm{D}(\mathrm{BTC})$ & $\mathrm{D}(\mathrm{SVI})$ & $\mathrm{D}(\mathrm{VIX})$ \\
\hline & Coefficient & $-0.0139^{* * *}$ & $0.0208^{* * *}$ & -0.0051 \\
\hline \multirow[t]{3}{*}{ Co-integrating equation (2) } & Standard deviation & 0.0037 & 0.0057 & 0.0039 \\
\hline & $\mathrm{t}$ value & -3.7744 & 3.6354 & -1.2972 \\
\hline & Coefficient & $0.0186^{* * *}$ & $-0.0333^{* * *}$ & 0.0021 \\
\hline \multirow[t]{3}{*}{ Co-integrating equation (3) } & Standard deviation & 0.0052 & 0.0081 & 0.00560 \\
\hline & $\mathrm{t}$ value & 3.5346 & -4.0969 & 0.3765 \\
\hline & Coefficient & $0.1037^{* * *}$ & $-0.1032^{* * *}$ & -0.0081 \\
\hline \multirow[t]{3}{*}{ BTC } & Standard deviation & 0.0274 & 0.0423 & 0.0291 \\
\hline & $\mathrm{t}$ value & 0.7826 & -2.4376 & -0.2786 \\
\hline & Coefficient & $0.0527^{* * *}$ & 0.0208 & 0.0192 \\
\hline \multirow[t]{3}{*}{ SVI } & Standard deviation & 0.0181 & 0.0280 & 0.0193 \\
\hline & t value & 2.8992 & 0.7410 & 0.9942 \\
\hline & Coefficient & -0.0098 & 0.0028 & -0.0388 \\
\hline \multirow[t]{3}{*}{ VIX } & Standard deviation & 0.0262 & 0.04047 & 0.02785 \\
\hline & $\mathrm{t}$ value & -0.3752 & 0.0698 & -1.3941 \\
\hline & Coefficient & 0.0027 & 0.0020 & $-5.13 E-05$ \\
\hline \multirow[t]{2}{*}{$\mathrm{C}$} & Standard deviation & 0.0020 & 0.0031 & 0.0021 \\
\hline & $\mathrm{t}$ value & 1.3436 & 0.6529 & -0.0237 \\
\hline $\mathrm{R}$ squared & & 0.0353 & 0.0225 & 0.0325 \\
\hline Adj. R squared & & 0.0316 & 0.0187 & 0.0288 \\
\hline
\end{tabular}

Significant level of ${ }^{* * *} 1 \%,{ }^{* *} 5 \%$, and ${ }^{*} 10 \%$.

TABLE 7: Granger causality test results for the variables in natural logarithm.

\begin{tabular}{lc}
\hline Null hypothesis & Prob. \\
\hline GOLD does not influence BTC & 0.9397 \\
BTC does not influence GOLD. & 0.3118 \\
JPY does not influence BTC & 0.5978 \\
BTC does not influence JPY & 0.9319 \\
SP500 does not influence BTC & 0.2092 \\
BTC does not influence SP500 & $0.0325^{* *}$ \\
SVI does not influence BTC & $4 . E-05^{* * *}$ \\
BTC does not influence SVI & $0.0018^{* * *}$ \\
USD does not influence BTC & 0.3888 \\
BTC does not influence USD & 0.8713 \\
VIX does not influence BTC & $0.0373^{* *}$ \\
BTC does not influence VIX & 0.1173 \\
SVI does not influence SP500 & 0.4206 \\
SP500 does not influence SVI & $0.0469^{* *}$ \\
VIX does not influence SP500 & $0.0098^{* * *}$ \\
SP500 does not influence VIX & 0.2837 \\
VIX does not influence SVI & $0.0074^{* * *}$ \\
SVI does not influence VIX & 0.3751 \\
\hline
\end{tabular}

Significant level of ${ }^{* * *} 1 \%,{ }^{* *} 5 \%,{ }^{*} 10 \%$.

Figure 5 shows all variables that affect BER in the long-term. The "feedback relationship" of the Granger causality appears in BER and the Google SVI. The VIX has a moderately significant Granger causality on the Bitcoin price in the long term.

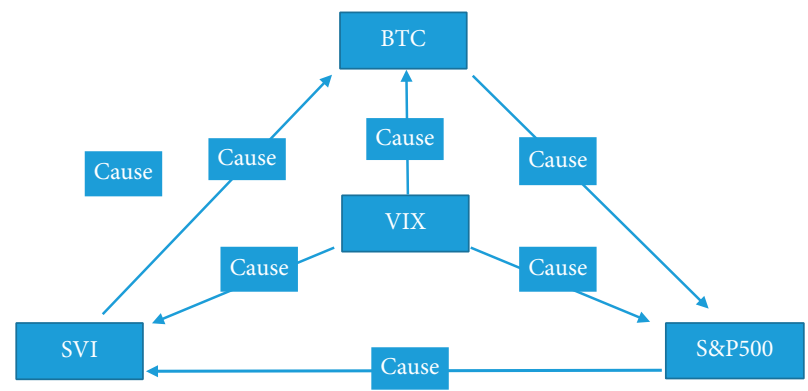

Figure 5: Granger Causality diagram among long-term variables.

\section{Conclusions}

The analysis results of this research suggested the co-integrated equilibrium and feedback relationship of the Granger causality between BER and Google SVI in the long term. The VIX influences mostly the BER in the long-term cointegration.

In addition to confirming the results of Cai et al. [4] and Dastgir et al. [21], the result confirmed the Granger causality between Google SVI and BER and the existence of the short- and long-term feedback between Google SVI and the $\mathrm{BER}$. The result also showed that there is a long-term co-integration relationship between the BER, VIX, and Google SVI. By observing Google SVI and the VIX, investors predict the future trend of the BER as BER has a long-term leading relationship with the S\&P500 index. The 
crypto-economy affects the real economy as the spillover effect of BER influences the S\&P500 [1]. When BER rises, the S\&P index should be viewed with optimism. Also, the VIX has a long-term leading relationship with BER as it drops with the rise of BER. The co-integration equilibrium between BER and Google SVI in the long-term leads to the feedback relationship of the Granger causality, which impacts Bitcoin price and causes the following: the prohibition of the Bitcoin trading exchange, the issuer's implementation of hard fork policy that damages investors' rights and confidence with no compensation, and information security issues. The price of Bitcoin fell back to the equilibrium value, which verifies the investor attention theory. The results help investors hedging or arbitrating engaged Bitcoin-related risks.

\section{Data Availability}

The data used to support the findings of this study are available from the corresponding author upon reasonable request.

\section{Conflicts of Interest}

The authors declare that they have no conflicts of interest.

\section{References}

[1] J. Kurka, "Do cryptocurrencies and traditional asset classes influence each other?" Finance Research Letters, vol. 31, pp. 38-46, 2019.

[2] B. M. Barber and T. Odean, "All that glitters: the effect of attention and news on the buying behavior of individual and institutional investors," Review of Financial Studies, vol. 21, no. 2, pp. 785-818, 2008.

[3] R. C. Merton, "A simple model of capital market equilibrium with incomplete information," The Journal of Finance, vol. 42, no. 3, pp. 483-510, 1987.

[4] Z. Cai, A. Liu, E. Lim, C.-W. Tan, and Z. Zheng, "Unraveling the effects of google search on volatility of cryptocurrencies," in Proceedings of the 39th International Conference on Information Systems (ICIS), Association for Information Systems. AIS Electronic Library (AISeL), San Francisco, CA, USA, December 2018.

[5] C. W. J. Granger, "Investigating causal relations by econometric models and cross-spectral methods," Econometrica, vol. 37, no. 3, pp. 424-438, 1969.

[6] C. W. J. Granger, "Some properties of time series data and their use in econometric model specification," Journal of Econometrics, vol. 16, no. 1, pp. 121-130, 1981.

[7] C. W. J. Granger and P. Newbold, "Spurious regressions in econometrics," Journal of Econometrics, vol. 2, no. 2, pp. 111-120, 1974.

[8] A. Urquhart and H. Zhang, "Is bitcoin a hedge or safe haven for currencies? an intraday analysis," International Review of Financial Analysis, vol. 63, pp. 49-57, 2019.

[9] J. Bleher and T. Dimpfl, "Today I got a million, tomorrow, I don't know: on the predictability of cryptocurrencies by means of Google search volume," International Review of Financial Analysis, vol. 63, pp. 147-159, 2019.
[10] A. Aouadi, M. Arouri, and F. Teulon, "Investor attention and stock market activity: evidence from France," Economic Modelling, vol. 35, pp. 674-681, 2013.

[11] N. Vlastakis and R. N. Markellos, "Information demand and stock market volatility," Journal of Banking \& Finance, vol. 36, no. 6, pp. 1808-1821, 2012.

[12] C. H. Huang, "Can google predict the stock return in Taiwan?" Master's Thesis for the Finance Dept, College of Management, National Taiwan University, Taiwan, China, 2013.

[13] F. Takeda and T. Wakao, "Google search intensity and its relationship with returns and trading volume of Japanese stocks," Pacific-Basin Finance Journal, vol. 27, pp. 1-18, 2014.

[14] Y. Zhang, W. Song, D. Shen, and W. Zhang, "Market reaction to internet news: information diffusion and price pressure," Economic Modelling, vol. 56, pp. 43-49, 2016.

[15] M. Qadan, D. Kliger, and N. Chen, "Idiosyncratic volatility, the VIX and stock returns," The North American Journal of Economics and Finance, vol. 47, pp. 431-441, 2019.

[16] P. R. Tsai, Y. C. Wang, and C. Z. Chang, "Study on the investor sentiment, firm characteristics, and stock returns in Taiwan," Taipei Economic Inquiry, vol. 45, pp. 273-322, 2017.

[17] D. P. Simon and R. A. Wiggins, "S \& P futures returns and contrary sentiment indicators," Journal of Futures Markets, vol. 21, no. 5, pp. 447-462, 2001.

[18] A. S. Lee, "Time-varying relationship of news sentiment, implied volatility and stock returns," Applied Economics, vol. 48, pp. 4942-4960, 2016.

[19] M. M. Copeland and T. E. Copeland, "Market timing: style and size rotation using the VIX," Financial Analysts Journal, vol. 55, no. 2, pp. 73-81, 1999.

[20] P. Dennis, S. Mayhew, and C. Stivers, "Stock returns, implied volatility innovations, and the asymmetric volatility phenomenon," Journal of Financial and Quantitative Analysis, vol. 41, no. 2, pp. 381-406, 2006.

[21] S. Dastgir, E. Demir, G. Downing, G. Gozgor, and C. K. M. Lau, "The causal relationship between bitcoin attention and bitcoin returns: evidence from the copula-based granger causality test," Finance Research Letters, vol. 28, pp. 160-164, 2019.

[22] C. Nelson and C. Plosser, "Trends and random walks in macroeconomic time series: some evidence and implications," Journal of Monetary Economics, vol. 10, no. 2, pp. 139-162.

[23] G. Hondroyiannis and E. Papapetrou, "Macroeconomic influences on the stock market," Journal of Economics and Finance, vol. 25, no. 1, pp. 33-49, 2001.

[24] C. Sims, "Macroeconomics and reality," Econometrica, vol. 48, pp. 1-47, 1980.

[25] R. F. Engle and C. W. J. Granger, "Co-integration and error correction: representation, estimation, and testing," Econometrica, vol. 55, no. 2, pp. 251-276, 1987.

[26] H. Akaike, "Information theory as an extension of the maximum likelihood principle," in Springer Series in Statistics Book Series, B. Petrov, F. Csaki, and A. Kiado, Eds., Springer, Budapest, Hungary, 1973.

[27] C. J. Hsieh, "An empirical analysis of bitcoin exchange rate," Master's Thesis for the EMBA Program, Department of Economics, National Taiwan University, Taiwan, China, 2017.

[28] Y. Hamao, R. W. Masulis, and V. Ng, "Correlations in price changes and volatility across international stock markets," Review of Financial Studies, vol. 3, no. 2, pp. 281-307, 1990.

[29] D. A. Dickey and W. A. Fuller, "Distribution of the estimators for autoregressive time series with a unit root," Journal of the American Statistical Association, vol. 74, no. 366a, pp. 427431, 1979. 
[30] P. C. B. Phillips and P. Perron, "Testing for a unit root in time series regression,” Biometrika, vol. 75, no. 2, pp. 335-346, 1988.

[31] S. Johansen, "Statistical analysis of cointegration vectors," Journal of Economic Dynamics and Control, vol. 12, no. 2-3, pp. 231-254, 1988.

[32] S. Johansen and K. Juselius, "Maximum likelihood estimation and inference on cointegration - with applications to the demand for money," Oxford Bulletin of Economics and Statistics, vol. 52, no. 2, pp. 169-210, 1990. 